\title{
Using Global Initiative for Asthma guidelines to assess asthma severity in populations
}

\author{
R. Liard, B. Leynaert, M. Zureik, F-X. Beguin, F. Neukirch
}

\begin{abstract}
Using GINA guidelines to assess asthma severity in populations. R. Liard, B. Leynaert, M. Zureik, F-X. Beguin, F. Neukirch. (C)ERS Journals Ltd 2000.

ABSTRACT: The classification of asthmatics into severity categories is a crucial issue for assessing the asthma burden within a community, in which a proportion of patients is currently treated. There is no epidemiological method currently available.

The Global Initiative for Asthma (GINA) was used to classify 4,362 patients aged 16-45 yrs (49\% males, $42 \%$ taking inhaled corticosteroids), enrolled by 545 chest specialists in France with short standardized questionnaires including forced expiratory volume in one second (FEV1) measurements. Two independent GINA classifications were combined, one based only on symptoms and FEV1, and the other based only on current medication, to construct a final "symptom-FEV1 medication" classification.

Almost $40 \%$ of the patients classed as step 1, 30\% of those classed as step 2 and $13 \%$ of those classed as step 3 in the initial symptom-FEV1-classification, were allocated to categories of higher severity in the final classification. The approach was validated by showing that the proportions of: 1) patients considered by the physicians as having severe or moderately severe asthma; 2) patients with a history of hospital admission for asthma; and 3) patients with a history of emergency department visits for asthma, increased with severity steps in the final classification, for each step of the two initial independent classifications.

The treatment manage plan in the Global Initiative for Asthma was not developed for assessing severity of asthma but rather to describe the recommended therapy for asthma with different severity. This is the first attempt to assess the severity of asthma in a large population of asthmatics mostly taking treatment, based on the Global Initiative for Asthma guidelines. The authors propose this simple and pragmatic procedure for a potential classification which should be put to the test in other studies. Eur Respir J 2000; 16: 615-620.
\end{abstract}

Asthma is a growing public health problem in many countries around the world [1]. Although its prevalence has been mapped by several international studies, the distribution of asthma severity is not known. Epidemiological studies of the prevalence of the different categories of asthma severity are needed to assess the asthma burden and cost [2]. These studies are mostly crosssectional and subjects are investigated at a single time. There is no epidemiological method currently available to classify asthmatics within a population.

In the last three decades, attempts have been made to classify asthmatics, based on various criteria. In the 1970s and 1980s, most classifications were based on the frequency of attacks [3], the patients' perception of dyspnoea and their ability to perform physical activities [4], or on these symptoms plus nocturnal symptoms and quality of sleep [5]. The perception of symptoms and airflow limitation differs between patients, so other classifications consider objective items, such as pulmonary function [6-8]. Since 1990, many guidelines have been published, reporting consensus statements formulated by international panels of experts [9-11]. Those guidelines were not developed for assessing severity of asthma but rather to describe the recommended therapy for asthma with different severity.

\author{
National Institute for Health and Medica \\ Research, Paris, France. \\ Correspondence: R. Liard \\ INSERM U408 Epidémiologie \\ Faculté de Médecine X. Bichat \\ B.P.416 \\ 75870 Paris Cedex 18 \\ France \\ Fax: 33142263330 \\ Keywords: Asthma severity \\ classification \\ epidemiology \\ Global Initiative for Asthma (GINA) \\ population studies
}

Received: February 22000

Accepted after revision May 132000
The definition of asthma severity based on clinical or functional features is inappropriate for cross-sectional population studies, in which a proportion of subjects is under treatment. This is because in optimal asthma control symptoms should be absent or minimal, with minimal need for rescue inhaled $\beta_{2}$-agonists, no limitation of activities and (near) normal lung function. These goals are the same for all degrees of asthma severity. It is therefore difficult to distinguish asthma severity from asthma control [12].

Medication use, as suggested by some studies [13, 14], is also inadequate for accurate classification of asthmatics, because when data for a cross-sectional study are collected, the patients will have different degrees of management. Some will be correctly treated and will have well controlled asthma, whereas some may be overtreated, and others, probably most, may be undertreated [15].

The description of asthma severity in a population should therefore, include the intensity of symptoms, airflow impairment and the intensity of treatment regimens.

The aim of this study was to develop a simple and pragmatic procedure for applying the international consensus guidelines, to classify currently treated asthmatics into severity categories in population studies, using information about symptoms, pulmonary function and asthma medication. 


\section{Patients and methods}

\section{Data collection}

For this study, some of the data collected in a large cross-sectional study of asthmatics attending private practice chest specialists, described elsewhere [16] was used. Five-hundred and forty-five chest specialists throughout France included all their asthmatic patients aged 6-76 yrs, examined from May 3rd-28th 1993. Each patient could be included only once. Data were collected by means of a short standardized questionnaire completed by physicians, including questions on patients' age, height and sex, history of visits to emergency departments and hospital admissions for asthma throughout the patient's life, and a description of current asthma status: frequency of symptoms, nocturnal asthma, exacerbations, and physical activity limitation. The questions were developed from the International Consensus Report on diagnosis and treatment of asthma [9]. The physician reported if he was examining the patient for the first time (new patient), the asthma medication the patient was taking when he came for the visit and any possible treatment modifications prescribed on that occasion. The physician was also asked to classify the patient into one of four asthma severity categories (mild, moderate, moderately severe and severe) according to his clinical judgement. The results and date of the most recent spirometry measurements were to be reported.

Predicted values of the forced expiratory volume in one second (FEV1) from age and height using the European Community for Steel and Coal (ECSC) reference equations [17] were calculated. All adults aged 16-45 yrs for whom the FEV1 had been determined during the visit or in the previous six months were included in this analysis $(\mathrm{n}=4,362)$.

\section{Classification of asthma}

The Global Initiative for Asthma (GINA) [11] was used. Two independent GINA classifications were combined, the first based on symptoms and FEV1 and the second on current medication, to construct a final "symptom-FEV1medication" classification. The procedures are described below.

Classification according to symptom and forced expiratory volume in one second. Step 1 (intermittent): patients with all the following characteristics: asthma symptoms (exacerbations) $<1$ time a week, night-time asthma $<2$ times a month, asymptomatic between exacerbations, FEV1 $\geq 80 \%$ predicted, and exacerbations not affecting activity.

The patients not classified as step 1 were assigned to the other steps in a downward manner as follows. Step 4 (severe persistent): This included patients with FEV1 $\leq 60 \%$ predicted, or physical activities limited by asthma. Step 3 (moderate persistent): patients with $60 \%<\mathrm{FEV} 1$ $<80 \%$ predicted, daily symptoms, or night-time asthma $>1$ time a week. Step 2 (mild persistent): this group includes all patients not allocated to the other steps. They have a FEV $1 \geq 80 \%$ predicted and at least one of the following: asthma symptoms $\geq 1$ time a week but $<1$ time per day, night-time asthma $>2$ times a month but $\leq 1$ time a week, or symptoms between exacerbations. Exacerbations may affect activities, as for step 3, but physical activities are not limited by asthma [11].

Classification according to current asthma medication. The GINA recommendations for controller medications were used, to classify patients based on the asthma treatment they were taking when they came for their visit, regardless of the physician's prescription at the end of the visit. Step 4: oral corticosteroids, or inhaled corticosteroids $>2,000 \mu \mathrm{g} \cdot \mathrm{day}^{-1}$, or $800-2,000 \mu \mathrm{g} \cdot \mathrm{day}^{-1}$ inhaled corticosteroids plus theophylline; Step 3: inhaled corticosteroids $800-2,000 \mu \mathrm{g} \cdot \mathrm{day}^{-1}$, without theophylline; Step 2: inhaled corticosteroids $<800 \mu \mathrm{g} \cdot \mathrm{day}^{-1}$, or nedocromil, or theophylline without oral corticosteroids; Step 1: no controller medication (none of the above) [11].

Final "symptom-forced expiratory volume in one second (FEV1)-medication" classification. The final severity step was the highest of the steps each patient was assigned to in the two independent classifications. Thus, for patients in step 1 of the symptom-FEV1 classification, the final classification was based on medication (these patients were either mild or well-controlled asthmatics, with a possible risk of over-treatment). Conversely, for those with no current controller treatment, including newly diagnosed patients, (step 1 of the medication classification), the final step was that of the symptom-FEV1 classification.

\section{Statistical analysis}

The difficulty with devising a classification of asthmatics into severity categories is that there is no gold standard to validate it. The rationale of the approach in this study was that in order to classify asthmatics receiving treatment it is necessary to consider symptoms and lung function level together with current medication, rather than either of these alone. To validate the approach the authors tested the value of considering: 1) medication in addition to symptoms and FEV1, and 2) symptoms and FEV1 in addition to medication. Three severity criteria were used which included: being considered by the physician as having severe or moderately severe asthma; having a history of hospital admission for asthma; and having a history of emergency department visits for asthma. The frequency of each of the three severity criteria in the final classification severity categories were compared, for each step of the symptom-FEV1 classification on the one hand, and for each step of the medication classification on the other.

The SAS-PC (SAS Institute Inc., NC, USA) statistics package was used. Contingency tables were analysed using chi-squared tests. Logistic regression models were used to calculate the odds-ratios (OR) of the three severity criteria associated with one-step increase in the final classification.

\section{Results}

The characteristics of the 4,362 patients included in the study are described in table 1 . Of the 1,359 patients seen for the first time by the physician, 811 had no asthma 
Table 1. - Characteristics of the study population

Subjects $n$

4,362

Age, yrs, mean (sd)

Sex M:F

$30.3(8.7)$

Frequency of exacerbations

$<1$ a month

$<1$ a week

$1-2$ a week

$>2$ a week

daily

Night-time asthma symptoms

$<2$ times a month

$>2$ times a month

1 time a week

several per week

Symptomatic between exacerbations

Limitation of physical activity

none

occasional

important

FEV1 \% pred

$\geq 80$

$60-80$

$<60$

Classification into severity categories

according to the physician

mild

moderate

moderately severe

severe

Use of "as-needed" short-acting $\beta_{2}$-agonist

none

$<4$ times a week

on most days

several times per day

Medication taken at the time of the visit:

Nedocromil

Theophylline

Inhaled corticosteroid

none

$<800 \mu \mathrm{g} \cdot \mathrm{day}^{-1}$

$800-2,000 \mu \mathrm{g} \cdot$ day $^{-1}$

$>2,000 \mu \mathrm{g} \cdot$ day $^{-1}$

Oral corticosteroid

History of hospital admissions for asthma

History of emergency department visits

for asthma

Data presented as percentage of population unless otherwise stated. FEV1: forced expiratory volume in one second.

treatment, and 3,003 individuals were current patients of the physicians that included them in the study. For $69.7 \%$ of them $(n=2,092)$ there was no change in medication category between the current treatment at the start of the visit and the treatment prescribed at the end of the visit.

Table 2 shows the number of patients assigned to each step of the final "symptom-FEV1-medication" classification, according to their position in the two independent "symptom-FEV1" and "medication" classifications.

Of the 953 patients classified as step 1 in the symptomFEV1 classification, only $575(60.3 \%)$ were in step 1 of the final classification (where current medication was also taken into account), $21.7 \%$ shifted to step $2,14.7 \%$ to step 3 , and $3.2 \%$ to step $4 ; 30.3 \%$ of the 1,368 patients classified as step 2 in the symptom-FEV1 classification, and $13.1 \%$ of the 1,269 patients classified as step 3 , were allocated to categories of higher severity in the final classification.

Figure 1a shows that the proportion of patients classified by physicians as having severe or moderately severe asthma increased sharply with the steps of the final classification. The OR associated with one-step increase in a logistic regression model was 6.6 (95\% confidence interval $(\mathrm{Cl})=5.8-7.5)$. When other possible classifications, based on FEV1 alone, symptoms alone, and medication alone, were tested the OR were lower: 4.7 (4.25.2), 3.7 (3.3-4.0), and $4.1(3.6-4.6)$, respectively.

Figures $1 \mathrm{~b}$ and $1 \mathrm{c}$ show that the proportions of patients having a history of hospital admission for asthma, and having a history of emergency department visits for asthma also increased with severity steps. The OR associated with one-step increase in the final classification were 2.9 (2.5-3.2) for hospital admissions and 2.1 (1.92.2) for emergency department visits. The ORs were lower when the other possible classifications were tested.

Table 3a shows that the percentage of patients with the first severity criterion "being considered by the physician as having severe or moderately severe asthma" increased significantly with severity steps in the final classification, for each step of the symptom-FEV1 classification. For example, for step 1 of the symptom-FEV $1,0.5 \%$ of patients were considered as having severe or moderately severe asthma in step 1 of the final classification, $1.5 \%$ in step 2 , $6.4 \%$ in step 3 and $29.0 \%$ in step 4 . There is a similar pattern for step 2 and step 3 of the symptom-FEV1 classification. This indicates that taking medication into account also provides useful additional information. Table $3 \mathrm{~b}$ shows that the percentage of patients with that severity criterion increased significantly with severity steps in the final classification, for each step of the medication classification: this shows the value of taking symptoms and FEV1 into account, in addition to medication.

The results were similar for the two other criteria: a lifelong history of hospital admission for asthma (table 4) and a lifelong history of emergency department visits for asthma (table 5).

\section{Discussion}

This is the first attempt to assess the severity of asthma based on the GINA guidelines in a large population of asthmatics mostly taking treatment. The aim was not to propose new scores, as this would probably result in conflicting classifications as shown in previous studies [18] and the authors had no criteria with which to choose the best score. The relevance of the guidelines to reality were also not assessed, as this has been carried out in other studies [19]. The aim of this study was to apply guidelines that had been developed for clinical use to cross-sectional population studies.

Various guidelines have been published in the last few years [20]. This study used the GINA guidelines, which are the most widely recognized, although they were published 2 yrs after the data were collected. Its use was considered valid for this study, because the study questionnaire was developed from the International Consensus Report [9], and there is little difference between GINA and ICR guidelines in the items and procedures 
Table 2. - Final severity categories to which patients were assigned by combining the symptom-forced expiratory volume in one second and medication classifications

\begin{tabular}{|c|c|c|c|c|}
\hline \multirow[b]{2}{*}{$\begin{array}{l}\text { Symptom-FEV1 } \\
\text { classification }\end{array}$} & \multicolumn{4}{|c|}{ Medication classification } \\
\hline & $\begin{array}{c}\text { Step 1 } \\
n=2,026\end{array}$ & $\begin{array}{l}\text { Step } 2 \\
n=854\end{array}$ & $\begin{array}{l}\text { Step } 3 \\
n=913\end{array}$ & $\begin{array}{l}\text { Step } 4 \\
n=540\end{array}$ \\
\hline Step 1: intermittent $N=953$ & Final step $1 \mathrm{n}=575$ & Final step $2 \mathrm{n}=207$ & Final step $3 n=140$ & Final step $4 n=31$ \\
\hline Step 2: mild persistent $\mathrm{N}=1,368$ & Final step $2 n=659$ & Final step $2 n=295$ & Final step $3 n=312$ & Final step $4 n=102$ \\
\hline Step 3: moderate persistent $N=1,269$ & Final step $3 n=585$ & Final step $3 n=239$ & Final step $3 n=278$ & Final step $4 n=167$ \\
\hline Step 4: severe persistent $N=743$ & Final step $4 \quad n=207$ & Final step $4 \mathrm{n}=113$ & Final step $4 n=183$ & Final step $4 n=240$ \\
\hline
\end{tabular}

$\mathrm{N}$ : number of patients in each medication or symptom classification; $n$ : number of patients in combined classification; FEV1: forced expiratory volume in one second.

used for classification. In both, the lung function level can be assessed from either peak expiratory flow (PEF) or FEV1 measurements. Only FEV1 was available for this analysis. It should be noted that in the latest versions of the GINA document, severity classification is based on PEF rather than FEV1.
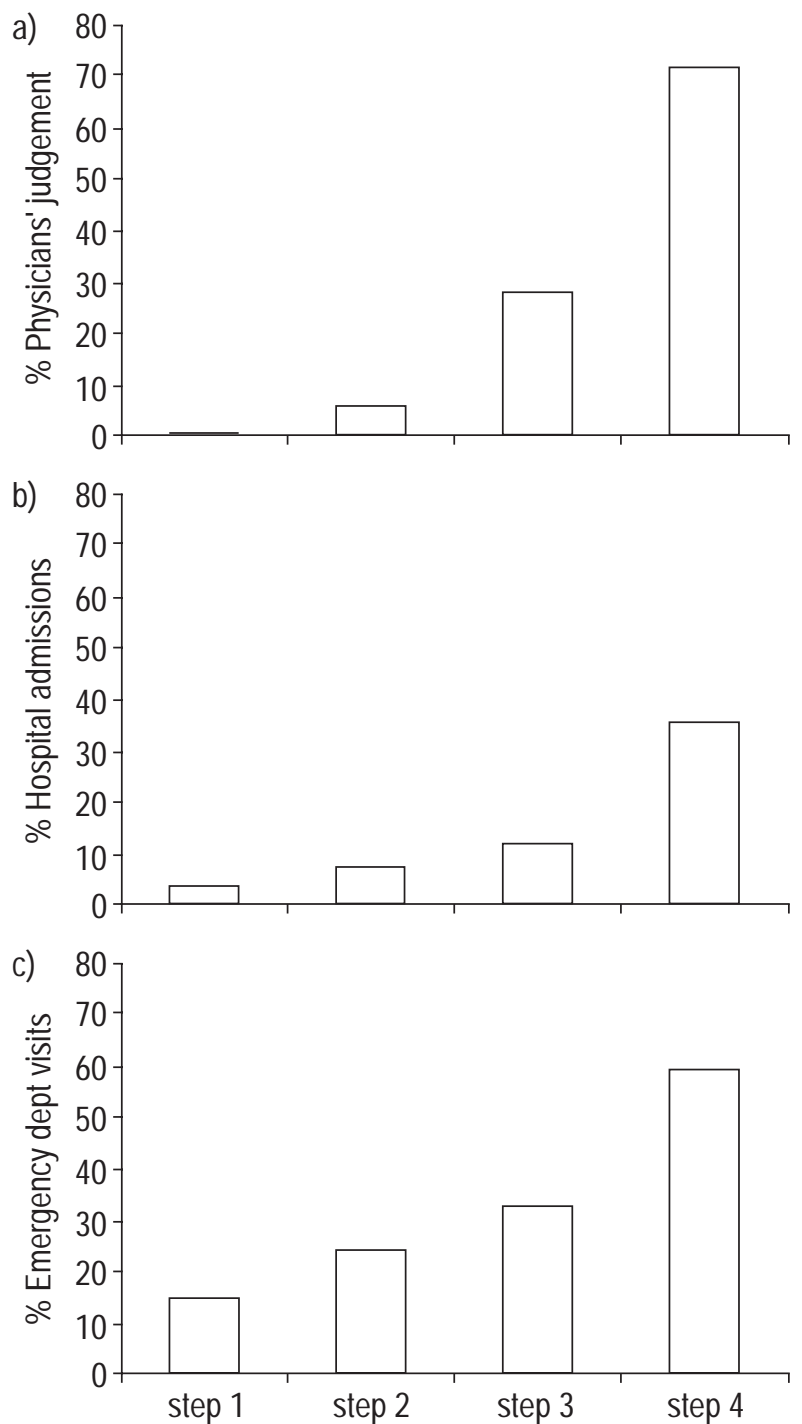

Fig. 1. - Proportion of patients a) classified by physicians as having severe or moderately severe asthma, b) having a history of hospital admission for asthma, and c) having a history of emergency department visit for asthma, for each step of the final symptoms-FEV1-medication classification.
Because guidelines were designed to be applied to individuals they are not easily applied to a population. Although the GINA categories are slightly more explicit than those of the ICR, it is almost impossible to design algorithms that use all the levels of all the variables. For example, there is little difference between "continuous symptoms" (step 4) and "symptoms daily" (step 3); exacerbations "may affect activity and sleep" in step 2 and step 3. It is therefore necessary to consider some items for some steps and other items for other steps, and decisions may be somewhat arbitrary. The authors tried to follow the classification rules as closely as possible. For the symptomFEV1 classification, the patients with intermittent asthma were first identified and then the characteristics that best described the three steps of persistent asthma in a downward stepwise approach were considered, because the presence of one of the severity features is sufficient to place a patient in that category. Daily use of "as-needed" inhaled $\beta_{2}$-agonists was not considered because not all patients use this medication in the same way: one individual may use it for vigorous exercise whereas another uses it to accomplish some basic activity of daily living [13]. No information concerning the type of use was available in this study. Moreover, the use of "as-needed" inhaled $\beta_{2}$-agonists is strongly correlated with asthma symptoms and exacerbations and is unlikely to provide valuable independent information. For the medication classification, the management guidelines were followed but long-acting $\beta_{2}$ agonists were not considered, as they were not in use at the time of data collection. The association of $800-2,000$ $\mu \mathrm{g}$ inhaled corticosteroid plus theophylline to assign subjects to medication class 4 , as well as inhaled corticosteroid $>2,000 \mu \mathrm{g}$, or oral corticosteroid was used. No information about compliance with treatment, a major problem in asthma, as in all chronic diseases [21] was available. In future studies, patients should be classified according to the medication actually taken rather than on the basis of prescriptions.

In combining the initial symptom-FEV1 classification and medication classification to obtain the final severity scores, it could have been considered that if patients had the same score for both classifications, then there was some asthma control by medication and the patient should be assigned to a higher severity category. The authors did not do this because it might have led to an overestimation of asthma severity. This is even more relevant when considering most types of asthma medication are inhaled through metered-dose inhalers and it has been shown that misuse of these devices is common [22]. Asthma severity in a population of asthmatics is a continuum rather than a 
Table 3. - Percentage of patients classified by physicians as having severe or moderately severe asthma, in each category of the final symptom-forced expiratory volume in one second (FEV1)-medication classification

\begin{tabular}{lccccc}
\hline & \multicolumn{3}{c}{ Final symptom-FEV1-medication classification } & \\
\cline { 2 - 4 } & Step 1 & Step 2 & Step 3 & Step 4 & $\mathrm{p}$-value \\
\hline Symptom-FEV1 classification & 0.5 & 1.5 & 6.4 & 29.0 & $\mathrm{p}<0.001$ \\
Step 1 & & 6.5 & 27.6 & 47.1 & $\mathrm{p}<0.001$ \\
Step 2 & & 30.0 & 71.3 & $\mathrm{p}<0.001$ \\
Step 3 & & & 76.2 & - \\
Step 4 & 0.5 & 4.1 & 18.6 & 57.0 & $\mathrm{p}<0.001$ \\
Medication classification & & 7.6 & 33.5 & 63.7 & $\mathrm{p}<0.001$ \\
Step 1 & & 32.3 & 80.3 & $\mathrm{p}<0.001$ \\
Step 2 & & & 75.0 & - \\
Step 3 & & & & \\
Step 4 & & & & \\
\hline
\end{tabular}

series of steps. The stepwise approach is operational and it is obvious that there is a certain heterogeneity within each category. Although undertreatment of asthma is currently the most frequent situation in populations [15], overtreatment might occur in specific communities. In which case, the classification used in this study would lead to an overestimation of asthma severity.

The classification the authors suggest is simple to use in population studies. It may even be considered simplistic. More complicated scales of disease severity based on the intensity of symptoms, airflow impairment and the management protocol have been proposed [13, 14, 23]. However, one major point is almost never considered: inhaled corticosteroids are currently the most widely used controller treatment for asthma, and in guidelines, all inhaled corticosteroids and devices are treated as being similar in potency and lung availability, which is probably not the case [20]. Because detailed information on inhaled corticosteroid use (molecule, type of device) is usually not available in population studies, there is no point in developing complicated medication scores, which would reflect reality no more than the simple classification used here. Nevertheless the development of more potent inhaled corticosteroids (such as fluticasone, which was not available at the time of data collection) should lead to considering doses in a standardized way, for example as beclomethasone equivalents.

An operational classification method may also be needed in large clinical trials performed to test medications for patients with a particular level of asthma severity, or when the proportion of patients of each severity category is determined before inclusion. The approach used in this study might be useful in such settings: patients would be initially classified by means of the method described, with the possibility to modify the classification using longitudinal data. It is noteworthy that in this study most of the patients that were currently treated by the physicians that included them in the study had no change in medication category between the treatment at the start of the visit and the treatment prescribed at the end of the visit. This suggests that the patients were considered as adequately treated and the physician had a definite opinion of the severity stage. The physicians' opinion correlated well with the classification in this study, thereby validating the approach.

To conclude, the Global Initiative for Asthma guidelines can be used to classify asthmatics receiving treatment into severity categories, taking symptoms, forced expiratory volume in one second and current medication into account. The authors propose this simple and pragmatic procedure for a potential classification which should be put to the test in other studies.

\footnotetext{
Acknowledgements. The authors acknowledge the support of the Association pour les études en pneumologie libérale, and particularly T. Lepage (Association des pneumologues de l'lle de France), Y. Martinat (Société alpine des pneumologues libéraux) and Y. Rogeaux (Association des pneumologues de la Région Nord). Data collection for the initial study was supported by Laboratoires FISONS. The authors are also indebted to all the chest specialists who enrolled the patients in the study.
}

Table 4. - Percentage of patients with a history of hospital admission for asthma, in each category of the final symptomforced expiratory volume in one second (FEV1)-medication classification

\begin{tabular}{|c|c|c|c|c|c|}
\hline & \multicolumn{4}{|c|}{ Final symptom-FEV1-medication classification } & \multirow[b]{2}{*}{ p-value } \\
\hline & Step 1 & Step 2 & Step 3 & Step 4 & \\
\hline \multicolumn{6}{|l|}{ Symptom-FEV1 classification } \\
\hline Step 1 & 3.4 & 3.9 & 14.4 & 23.3 & $\mathrm{p}<0.001$ \\
\hline Step 2 & & 6.9 & 16.2 & 40.0 & $\mathrm{p}<0.001$ \\
\hline Step 3 & & & 9.8 & 37.8 & $\mathrm{p}<0.001$ \\
\hline Step 4 & & & & 33.9 & - \\
\hline \multicolumn{6}{|l|}{ Medication classification } \\
\hline Step 1 & 3.4 & 5.9 & 3.5 & 6.6 & $\mathrm{p}=0.05$ \\
\hline Step 2 & & 7.0 & 14.5 & 18.5 & $\mathrm{p}<0.001$ \\
\hline Step 3 & & & 16.9 & 35.8 & $\mathrm{p}<0.001$ \\
\hline Step 4 & & & & 48.3 & - \\
\hline
\end{tabular}


Table 5. - Percentage of patients with a history of emergency department visits for asthma, in each category of the final symptom-forced expiratory volume in one second (FEV1)-medication classification

\begin{tabular}{lccccc}
\hline & \multicolumn{3}{c}{ Final symptom-FEV1-medication classification } & \\
\cline { 2 - 4 } & Step 1 & Step 2 & Step 3 & Step 4 & p-value \\
\hline Symptom-FEV1 classification & & & & \\
Step 1 & 14.5 & 19.4 & 28.5 & 43.3 & $\mathrm{p}<0.001$ \\
Step 2 & & 24.6 & 42.5 & 60.8 & $\mathrm{p}<0.001$ \\
Step 3 & & 29.8 & 62.3 & $\mathrm{p}<0.001$ \\
Step 4 & & & 58.2 & - \\
Medication classification & 14.5 & 19.4 & 19.1 & 34.2 & $\mathrm{p}<0.001$ \\
Step 1 & & 29.4 & 38.3 & 50.0 & $\mathrm{p}<0.001$ \\
Step 2 & & 40.9 & 59.3 & $\mathrm{p}<0.001$ \\
Step 3 & & & 69.6 & - \\
Step 4 & & & &
\end{tabular}

\section{References}

1. European Community Respiratory Health Survey. Variations in the prevalence of respiratory symptoms, selfreported asthma attacks, and use of asthma medication in the ECRHS. Eur Respir J 1996; 9: 687-695.

2. Sterk PJ, Buist SA, Woolcock AJ, et al. The message from the World Asthma Meeting. Eur Respir J 1999; 14: $1435-1453$.

3. Charpin J, Orehek J, Vervloet D. Asthme bronchique. In: Charpin J, Vervloet D, eds. Allergologie. Paris: Flammation, 1992; pp. 450-452.

4. Di Maria GU, Bellofiore S, Mistretta A. The staging of asthma and therapeutic implications. Eur Respir Rev 1993; 3: 387-390.

5. Busse WW, Wilson AF. Workshop 5: assessment of efficacy. J Allergy Clin Immunol 1986; 78: 525-528.

6. Hargreave FE, Dolovich J, Newhouse MT. The assessment and treatment of asthma: a conference report. $J$ Allergy Clin Immunol 1990; 85: 1098-1111.

7. Brooks SM, Bernstein L, Raghuprasad PK, et al. Assessment of airway hyperresponsiveness in chronic stable asthma. J Allergy Clin Immunol 1990; 85: 1726.

8. Aas K. Heterogeneity of bronchial asthma. Sub-populations - or different stages of the disease. Allergy 1981; 36: $3-14$.

9. International Consensus Report on Diagnosis and Treatment of Asthma. Eur Respir J 1992; 5: 601-641.

10. British Thoracic Society. Guidelines for the management of asthma. Thorax 1993; 48: S1-S24.

11. National Heart Lung and Blood Institute. Global initiative for asthma. Global strategy for asthma management and prevention. NHLBI/VVHO workshop report. National Institutes of Health, Bethesda 1995. National Heart Lung and Blood Institute publication number 95-3659.
12. Cockcroft DW, Swystun VA. Asthma control versus asthma severity. J Allergy Clin Immunol 1996; 98: 10161018.

13. Busse WW, Maisiak R, Young KR Jr. Treatment regimen and side effects of treatment measures. Am J Respir Crit Care Med 1994; 149: S44-S50.

14. Wahlgren DR, Hovell MF, Matt GE, Meltzer SB, Zakarian JM, Meltzer EO. Toward a simplified measure of asthma severity for applied research. J Asthma 1997; 34: 291-303.

15. Bousquet J, Knani J, Henry C, et al. Undertreatment in a population of nonselected adult asthmatics. J Allergy Clin Immunol 1996; 98: 514-521.

16. Liard R, Segala C, Beguin FX, et al. Asthme en pneumologie libérale. Rev Mal Respir 1997; 14: 295-304.

17. Quanjer H, Tammeling GJ, Cotes JE, Pedersen OF, Peslin R, Yernault JC. Lung volumes and forced ventilatory flows. Eur Respir J 1993; 6(Suppl. 16): 5-40.

18. Gautier V, Rédier H, Pujol JL, et al. Comparison of an expert system with other clinical scores for the evaluation of severity of asthma. Eur Respir J 1996; 9: 58-64.

19. Barnes N. Do treatment guidelines reflect reality? Eur Respir Rev 1997; 7: 316-317.

20. Meijer RJ, Kerstjens HAM, Postma DS. Comparison of guidelines and selfmanagement plans in asthma. Eur Respir J 1997; 10: 1163-1172.

21. Postma DS, Koeter GH. Compliance with prescribed treatment in mild asthma. Eur Respir Rev 1996; 6: 54-56.

22. Liard R, Zureik M, Aubier M, Korobaeff M, Henry C, Neukirch F. Misuse of pressurized metered dose inhalers by asthmatic patients treated in French private practice. Rev Epidemiol Santé Publ 1995; 43: 242-249.

23. Morris NV, Abramson MJ, Rosier MJ, Strasser RP. Assessment of the severity of asthma in a family practice. J Asthma 1996; 33: 425-439. 